\section{Edyrcasaice

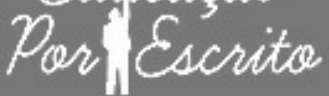

ARTIGO

\section{Editor}

Alexandre Anselmo Guilherme PUCRS, RS, Brasil

\section{Editor Assistente \\ Cibele Cheron}

PUCRS, RS, Brasil

\section{Editores Associados}

Bruno Antonio Picoli

Universidade Federal da Fronteira Sul, Chapecó, SC, Brasil

Pricila Kohls dos Santos Universidade Católica de Brasília, Brasília, DF, Brasil

Renato de Oliveira Brito

Universidade Católica de Brasilia, Brasilia, DF, Brasil

Elisa Ustarroz

PUCRS, Porto Alegre, RS, Brasil

\section{ISSN 2179-8435}

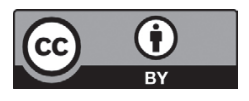

Este artigo está licenciado sob forma de uma licença Creative Commons Atribuiçāo 4.0 Internacional, que permile uso irrestrito, distribuiçăo e reproduçāo seja corretamente citada

\title{
Tangenciamentos entre a filosofia da diferença e o ensino de Matemática para todos
}

\author{
Approximations between the philosophy of difference and \\ teaching of the Mathematic for all
}

José Eduardo de Oliveira Evangelista Lanuti $\odot$ Universidade Federal de Mato Grosso do Sul (UFMS), Três Lagoas, MS, Brasil.

\section{RESUMO}

Ao reverter o pensamento platônico, dedicado à busca pela semelhança ao afirmar a necessidade da instituição de modelos para serem seguidos, Deleuze, inspirado pelas obras de Bergson, apresenta o conceito de diferença. Ainda que o filósofo não tenha criado conceitos pensando especificamente na escola, ao considerar cada pessoa como um ser único, a sua filosofia desestrutura todos os tipos de negação do direito à diferença, que são formas de excluir aqueles que, injustamente, são tidos como os diferentes. É pelo estudo dos motivos, infundados, que têm a pretensão de justificar a categorização e a exclusão de alguns alunos, que poderemos propor um ensino, de fato, para todos. A Matemática ainda é concebida como uma disciplina à parte das demais, de alcance de apenas uma parcela dos alunos que, supostamente, são capazes de entendê-la. Nessa perspectiva, ainda tão presente nas escolas, muitos são excluídos. Neste texto apresento os encaminhamentos de uma pesquisa de doutorado em andamento que tem como matéria-prima de investigação uma formação docente em serviço com professores do Ensino Fundamental. As aproximações entre a filosofia deleuzeana e o ensino de Matemática têm provocado mudanças de concepções e de ações dos professores participantes.

Palavras-chave: Inclusão escolar. Filosofia da diferença. Educação matemática. Ensino para todos.

\section{ABSTRACT}

Deleuze, inspired by Bergson's works, presents the concept of difference itself by reversing the Platonic thinking, dedicated to the search for the similarity when claiming the necessity to create models to be followed. Even though the philosopher didn't create concepts thinking specifically in the school, when he considers each person as a single one, his Philosophy deconstructs all kinds of negation of the right to difference, which are ways of excluding those who are unfairly considered different. It is through the study of the reasons, unfounded, that it is intended to justify a categorization and exclusion of some students, that we will be able to propose a teaching, in fact, for all. The Mathematic is still conceived as an isolated discipline, of reach of only a 
portion of the students, supposedly, are able to understand it. From this perspective, still so present in schools, many students are excluded. In this text, I present a Doctoral research in progress that has a training teacher of Basic Education in service as its raw material of investigation. The approximations between Deleuzean Philosophy and teaching of Mathematic have caused changes of conceptions and actions of the participating teachers.

Keywords: School inclusion. Philosophy of Difference. Mathematic education. Teaching for all.

\title{
Introdução
}

\begin{abstract}
A
inclusão escolar depende da garantia de acesso, permanência e participação na escola comum para todos os alunos, mas não basta que todos estejam integrados em um mesmo ambiente. Incluir exige uma mudança nas concepções, nas ações pedagógicas e na formação dos professores para que o ensino seja desenvolvido a partir do direito que todos os estudantes têm de aprender a partir das suas possibilidades, sem que existam comparações e discriminações de todo tipo. Esse é um assunto que desafia todos os envolvidos com Educação a repensarem a forma tradicional e excludente de planejar o ensino com base em um modelo idealizado de aluno.

A filosofia da diferença, apresentada por Gilles Deleuze, tem sido a inspiração de um grupo de professores que ensinam Matemática nos anos iniciais do Ensino Fundamental, do qual sou orientador, para pensar sobre as bases que sustentam a Educação. Como afirma Gallo (2016), ainda que Deleuze não tenha pensado diretamente sobre a escola, a sua filosofia tem muito a ver com as experiências vivenciadas no campo educacional. Realizamos encontros semanais de formação com os trinta e cinco professores dos anos iniciais do Ensino Fundamental (1으 ao 5ㅇ ano) de uma escola da rede municipal de ensino. Nessas reuniões discutimos sobre o ensino de Matemática desenvolvido na escola e, de forma colaborativa, temos encontrado na Filosofia de Gilles Deleuze os argumentos que sustentam o nosso entendimento sobre o que é um ensino inclusivo - para todos, indistintamente.

Os professores têm filmado alguns momentos das suas aulas e, nos encontros de formação, discutimos sobre as estratégias de ensino desenvolvidas por eles e sobre as possibilidades de melhorar o trabalho pedagógico, no sentido de ensinar Matemática a todos os alunos, independentemente dos rótulos, das supostas incapacidades e desprovimentos daqueles que são, injustamente, considerados diferentes. A estratégia de filmar e analisar as aulas foi inspirada no que Weisz e Sanchez (2011) denominam por Tematização da Prática.
\end{abstract}


A partir dessa formação, tenho desenvolvido uma pesquisa de doutorado ${ }^{1}$, de abordagem qualitativa, que tem como objetivo analisar como a formação proposta pode contribuir para uma mudança de concepções e de ações dos professores no que diz respeito ao desenvolvimento de um ensino de Matemática para todos. Meu objetivo, com este texto, é apresentar como o estudo da filosofia da diferença tem provocado uma mudança no modo de ensinar Matemática por parte dos professores participantes da formação que venho propondo enquanto formador.

As discussões que emergiram no início da formação, que ocorre desde maio de 2016, com a aprovação do Comitê de Ética em Pesquisa (CEP) da UNICAMP², estiveram voltadas à necessidade apresentada pelo grupo de professores de entender porque ainda existe um critério de normalidade para os seres, o que gera uma categorização dos sujeitos considerados fora de um padrão previamente estabelecido. Dentre as questões que temos feito para buscarmos maneiras de desenvolver estratégias de ensino capazes de ensinar Matemática a todos, está a seguinte: por que alguns alunos foram e ainda são excluídos?

Direcionar as práticas educacionais rumo à inclusão escolar depende do entendimento das questões de fundo, como as causas da exclusão de um grupo de alunos. Analisar essas causas foi o ponto de partida que tivemos para compreender as razões que fundamentam o pensamento revolucionário referente à inclusão escolar.

\section{Por que alguns alunos foram e ainda são excluídos?}

Vivemos em busca de modelos que representam o que somos e não quem somos, como se pudéssemos ser representados por uma característica, como se fossemos fragmentos de uma categoria unificadora que nos define. A escola ainda não reconhece a pluralidade dos tipos de conhecimentos, as infinitas formas de ser, de sentir e de aprender. Consequentemente, os grupos são instituídos e os estudantes são classificados, categorizados a partir de critérios infundados que nada revelam sobre quem, realmente, cada um é. A escola criou um ícone que representa o "bom aluno" (aquele que tira boas notas, que reproduz corretamente o que lhe foi explicado e realiza as tarefas conforme o professor solicitou etc.) e fez com que os não pretendentes a esse modelo fossem considerados incapazes, não aptos - "os diferentes".

\footnotetext{
1 Desenvolvida no Programa de Pós-Graduação em Educação da Universidade Estadual de Campinas (Unicamp), financiada pela Fundação de Amparo à Pesquisa do Estado de São Paulo (FAPESP). Vinculada ao Laboratório de Estudos e Pesquisas em Ensino e Diferença (LEPED), orientada pela Professora Doutora Maria Teresa Eglér Mantoan.

2 A pesquisa foi submetida e aprovada pelo comitê de Ética em Pesquisa da Universidade Estadual de Campinas (Unicamp), CAAE: 54026216.6 .0000 .5404 .
} 
Com o estudo realizado pelo grupo de professores sobre a filosofia da diferença, temos identificado quais estratégias desenvolvidas na escola ainda carregam consigo a ideia de um modelo idealizado de aluno. As adaptações curriculares, ambientes à parte, salas de recuperação de ciclos, por exemplo, são formas de diferenciar o ensino para aqueles que não respondem às expectativas da escola. Esse tipo de estratégia, que aparentemente inclui todos, reforça a improbidade de um sistema educacional pensado para alguns. A diferenciação de um recurso, a partir de determinada condição de deficiência do sujeito se faz necessária, mas sob hipótese alguma devemos pensar na diferenciação do ensino para alguns. Entendemos que o que precisa ser adaptado não fora pensado para todos e adaptar não é o caminho da inclusão.

Representar o ícone do aluno perfeito e determinar que todos os demais sejam pretendentes desse modelo tem a ver com o pensamento platônico, que negou a diferença e esteve alicerçado na busca pela semelhança entre as pessoas com base no ser idealizado, para o alcance de uma suposta verdade já determinada. A filosofia deleuzeana combate esse pensamento ao considerar todas as pessoas como seres em constante transformação, que se fazem da sua própria diferença, e não como sujeitos "per-feitos".

As ideias de impermanência e univocidade do ser colocam em xeque os modelos tidos como referência e, com isso, toda e qualquer justificativa para comparar as pessoas passa a ser infundada. Nessa perspectiva, as deficiências são transferidas do sujeito para o meio em que ele vive e isso nos faz pensar que existem, na verdade, pessoas em situação de deficiência - condição mutante, que se transforma a cada nova situação e, portanto, não há razões para a construção de uma identidade fixada na insuficiência, como comumente se relaciona a um determinado grupo de pessoas. Classificar as pessoas, identificando nelas características que podem ser comparadas têm a ver com a diversidade e não com a diferença, ou seja, com a diferença de alguns e não de todos. Essa, a meu ver, é a causa da exclusão!

Para Deleuze (segundo Schöpke, 2012) Aristóteles foi o responsável pela subordinação da diferença à diversidade. Ao conceber a diferença como um atributo de um corpo, ela passa a ser um conceito: uma definição precisa, generalizada, uma característica. Essa forma de conceber a diferença faz, pretensiosamente, uma classificação e uma categorização dos seres, pois não considera a diferença interna de cada pessoa, conforme Deleuze (1999), mas refere-se a uma diferença de grau, externa, a diferença "entre", que compara e estigmatiza os seres. Já a diferença em $s i$ - $a$ expressão única do ser, conforme Schöpke (2012) - escapa de toda e qualquer forma de representação, pois é mais do que a negação do idêntico, é a afirmação da diferença de natureza, interna ao ser, é o puro devir! A diferença de cada um difere a todo o momento de si mesma, não do outro; está além do gênero, da espécie, do número, do empírico, ou, como afirma Deleuze (2000), das distinções. 
O entendimento da filosofia da diferença tem permitido ao professores participantes da referida pesquisa lançar um novo olhar para o processo educacional. $O$ grupo tem passado a entender que a inclusão escolar não diz respeito a um grupo de estudantes considerados público-alvo da Educação Especial, mas a todos os alunos. Os professores têm chegado à conclusão de que a construção de uma escola inclusiva depende da desestabilização dos paradigmas educacionais alicerçados na busca pela homogeneização e que, para que isso aconteça, é necessário desviar o olhar voltado à diversidade (que considera os diferentes, os grupos, a representação) e direcioná-lo para a diferença de cada estudante.

\section{Como incluir todos na escola? Repensar o currículo, a formação, o ensino e a aprendizagem}

Desde a democratização do acesso ao ensino a escola deveria ter pensado em currículos, métodos, estratégias, recursos e materiais que favorecessem a participação de todos os alunos no processo educacional formal e regular. Entretanto, ainda prevalece o formato organizacional da escola que preconiza o conhecimento formal, mecanicista. Esperam-se respostas padronizadas e o subjetivo, o criador, o afetivo, conforme afirmou Mantoan (2006, 2014), é desconsiderado.

A formação docente, ainda que venha demonstrando uma preocupação com a questão da inclusão, ainda está presa na diversidade, na classificação dos sujeitos a partir de sua suposta insuficiência, no modelo médico, nos laudos, na equivocada pretensão de definir o que o outro é. As pesquisas educacionais, sobretudo no que se refere ao ensino de Matemática na perspectiva da inclusão, ainda estão focadas na criação de recursos e métodos de ensino específicos para uma determinada suficiência, como se todas as pessoas com Deficiência Intelectual, ou Síndrome de Down, por exemplo, aprendessem do mesmo modo. Há uma necessidade - equivocada - de definir o sujeito e categorizá-lo em uma identidade fixa que, na verdade, não representa o caráter mutante da diferença. O ser não é estático, tampouco aprende de forma previsível.

Ao considerar a aprendizagem como um processo controlável e determinável a partir de cada categoria de pessoas, os currículos são organizados de forma hierarquizada, como se o conhecimento fosse construído linearmente, em uma organização totalmente arborescente, puramente lógica. Essa metáfora foi utilizada por Deleuze e Guatarri (1996) para descrever como a construção do conhecimento ainda é considerada como algo hierarquizado, fragmentado, ramificado pelos galhos (que não se relacionam) das especializações, pertencentes a um tronco comum, que sustenta essa estrutura organizada linearmente. Para os autores, o conhecimento é, ao contrário, construído de forma rizomática, caótica, desordenada, imprevisível e, portanto, não há como prever o que e nem como cada pessoa aprende. Com 
base nesses autores, acredito que o próprio sujeito não tem plena consciência de como aprendeu, no momento em que a aprendizagem ocorre e, portanto, seria muita pretensão de um professor buscar formas de controlar o processo de construção do conhecimento de um aluno.

Os estudantes que não aprendem o que é determinado por aqueles que não vivenciam a escola a ponto de perceberem que não se aprende a mesma coisa, do mesmo modo em um mesmo tempo) são excluídos por meio de atividades adaptadas. Na formação que vem sendo desenvolvida com esse grupo ao qual me refiro, os professores vêm questionando a forma prescritiva e impermeável de organização do currículo utilizado pela escola.

Temos entendido que o currículo prescritivo prejudica alguns alunos pelo fato de não oportunizar o desenvolvimento dos seus talentos e a sua participação e aprendizagem a partir de suas possibilidades. Impõe-se o que deve ser ensinado, determina-se o momento adequado para se trabalhar com cada conteúdo, define-se a ordem, previsível, para que a aprendizagem ocorra, ou seja, é desconsiderado o que advém das relações entre os sujeitos - o devir. É imprescindível que, em uma escola caracterizada pela multiplicidade, os processos de ensino e de aprendizagem sejam encarados de outro modo e o currículo seja elaborado pelos próprios professores e alunos, que têm condições suficientes para definirem as metas que desejam alcançar, a partir do contexto específico de cada realidade.

A formação docente também deveria considerar as necessidades do professor para enfrentar os desafios de trabalhar com a diferença, com o múltiplo, com o imprevisível que é lidar com o outro. Nessa direção, o sistema educacional não deveria ter como meta a aprendizagem entendida como uma consequência direta e imediata do processo de ensino, mas no entendimento de que aprender tem a ver como um processo criativo e, muitas vezes, não relacionado diretamente ao que fora ensinado.

Conceber a aprendizagem como criação revela a necessidade de um currículo que se movimente, conforme aponta Tadeu (2002), um currículo que é feito por todos, a partir dos elementos imanentes que compõem o plano de trabalho da escola, definindo o seu contexto real, que sempre se atualiza e não por aqueles que vivenciam a experiência escolar "de fora". É necessário um trabalho menor, preciso, que considera as contingências de problemas escolares específicos a serem enfrentados em um dado momento.

Conforme Gallo (2016), primeiramente é preciso abandonar a ideia de que a aprendizagem está condicionada ao ensino e de que tudo o que é ensinado será, por consequência, aprendido. Ensinar e aprender são processos distintos e independentes e muitos alunos são excluídos por não fornecerem aos professores o retorno esperado sobre o que foi ensinado.

A escola necessita reorganizar as suas práticas de modo que cada um possa traçar o caminho que deseja para aprender. Ainda que a Matemática seja uma disciplina da área de exatas, há que se reconhecer que existem diversos 
caminhos a serem trilhados pelos alunos e que as pessoas aprendem coisas diferentes em tempos indetermináveis. Os próprios entes primitivos, da Geometria, são exemplos de que na Matemática há elementos que não podem ser definidos com exatidão.

Nessa direção, não cabe mais a ideia de esperar respostas generalizadas, uniformizadas, em tempos determinados. A escola, deve buscar sempre oferecer o melhor para que os seus alunos se desenvolvam, aprendam e conheçam o mundo e as outras pessoas que dele fazem parte, mas em hipótese alguma pode ter a pretensão de controlar o que é aprendido. Aprender tem a ver com um processo, livre e imprevisível, conforme Deleuze (2010).

O formato de organização dos currículos tradicionais e prescritivos, por exemplo, partem dessa concepção arbórea para explicar o processo de construção do conhecimento humano - visão reducionista, que compartimenta os saberes em disciplinas, conforme aponta Gallo (1999), que sugere uma ordem para que os conteúdos sejam ensinados e consequentemente aprendidos.

Consideramos que todos os estudantes sabem alguma coisa e que, portanto, podem sempre aprender. Nessa direção, o papel da escola é oferecer o máximo de informações, de recursos, de materiais e organizar situações com os alunos, para que todos possam aprender no seu caos, conectando os seus saberes, de forma subjetiva, pessoal e intransferível, realizando os seus próprios agenciamentos.

Oposta à representação clássica, que copia o mesmo, que reproduz, reconhece, universaliza, a ideia de conhecimento apresentada por Deleuze tem a ver com o modo com que cada um trata o generalizado e cria os seus próprios conceitos a partir dos seus saberes prévios. Sua filosofia aborda o acontecimento, o relativo, o circunstancial.

Uma boa formação é aquela que considera as experiências do professor e, nessas experiências - que são os fatos que o toca e o instiga a pensar e a criar soluções para o que vivencia no momento presente - os conteúdos curriculares, as diretrizes educacionais, dentre outras teorias, são buscadas como um dos meios possíveis para se pensar sobre possibilidades para enfrentar as necessidades locais, os problemas elaborados por um grupo específico em dado momento. É nesse sentido que a formação do docente em serviço é importante, pois viabiliza a reflexão dos professores sobre os problemas que acontecem no momento presente por meio da realização de estudos de caso. E, nesses estudos locais, não se tem a pretensão de generalizar uma estratégia, de maneira alguma indicando-a para que seja desenvolvida em outros contextos.

As situações de aprendizagem, pautadas na relação dos conteúdos acadêmicos com a vida cotidiana dos alunos, são formas de contextualizar as informações, de possibilitar a participação de todos e de permitir que cada um possa escolher de que modo será realizada determinada tarefa a partir do que tem sentido para si.

No campo da Educação Matemática é de extrema importância que sejam propostas situações que favoreçam a relação dos conteúdos à realidade dos alunos. Apesar de os conhecimentos matemáticos terem sido construídos e 
desenvolvidos a partir da necessidade humana, das tarefas cotidianas e reais dos povos, a maneira pela qual esses conhecimentos foram sendo sistematizados (a partir de uma linguagem própria, regras e teoremas abstratos etc.) fez com que a Matemática passasse a ser entendida como algo distante da realidade. É essencial, portanto, que o ensino dessa disciplina seja planejado e desenvolvido de modo a torná-la acessível a todos. E quando penso em todos, não me refiro a todas pessoas com alguma deficiência, uma vez que muitos alunos não considerados público-alvo da Educação Especial, apresentam muitas dificuldades em relação à Matemática. Não é a deficiência que define o sujeito, aliás, a diferença humana é indeterminável.

Conforme Mantoan (2002) temos de propor atividades abertas, diversificadas, de modo que os diferentes conhecimentos sejam valorizados. Rodas de conversa, debates, passeios, pesquisas, entrevistas e seminários são exemplos de atividades que incluem todos os estudantes e possibilitam a cada sujeito escolher o que quer fazer, a partir dos seus interesses. Nesses contextos educacionais, cada aula é vista como um plano em que os conteúdos podem ser trabalhados para que os assuntos discutidos sejam compreendidos, para sanar as dúvidas dos alunos, sem que exista uma determinação do que deve ser ensinado e/ou aprendido. O conhecimento é visto como uma criação, e não se indica como ele deve ser apresentado, provado.

O revés que a inclusão propõe é o de fazer com que a escola desempenhe o seu papel de ensinar e não de fazer o outro aprender o que está determinado nas normas educacionais que embrutecem o que é, naturalmente, livre: o aprender, que é sinônimo de transformação. Esse talvez seja o ponto crucial para se pensar em uma escola, definitivamente, de todos.

A partir das discussões nos encontros de formação e do entendimento das causas da exclusão, passamos a buscar meios de ensinar Matemática em uma perspectiva inclusiva com base na reflexão dos professores sobre as atividades desenvolvidas nas suas aulas.

\section{0 ensino de Matemática na perspectiva da Inclusão}

Após estudarmos as questões de fundo da inclusão escolar e entendermos que incluir tem a ver com a diferença de cada pessoa e não com a diferença de um grupo instituído com base na diversidade, passamos a pensar, especificamente, sobre o ensino de Matemática - disciplina ainda concebida para poucos, para uma minoria que "domina" o raciocínio lógico, as regras e teoremas generalizantes.

A aversão de muitos alunos em relação à Matemática não é assunto novo. Ferreira (1998, p.20), por exemplo, afirmou que

Educação Por Escrito, Porto Alegre, v. 10, n. 2, jul.-dez. 2019: e30767 
[...] ao perceberem a Matemática como algo difícil e não se acreditando capaz de aprendê-la, os estudantes, muitas vezes, desenvolvem crenças aversivas em relação à situação de aprendizagem, o que dificulta a compreensão do conteúdo e termina por reforçar sua postura inicial, gerando um círculo vicioso.

Durante os encontros formativos realizados com os professores polivalentes, tenho identificado as necessidades formativas desse grupo em relação ao desenvolvimento de práticas de ensino de Matemática que possibilitam o acesso de toda a turma aos conteúdos matemáticos, de modo que todos os alunos possam participar e aprender das aulas a partir de suas possibilidades, sem que sejam comparados entre si. Nosso objetivo tem sido construir contextos educacionais capazes de ensinar Matemática a partir das diversas possibilidades de aprendizagem que os sujeitos apresentam, de modo que os estudantes não se sintam incapazes de entender os seus conteúdos.

O desafio que temos enfrentado é o de pensar em um ensino como um ato de disponibilização, em que os professores organizam o seu trabalho para oferecer o máximo de elementos possíveis para que cada aluno escolha o que lhe serve, em um dado momento, para aprender. Em uma aula puramente expositiva isso não é possível e, nesse sentido, temos buscado possibilidades para a construção de situações de ensino com uma abordagem prática, que tenham sentido para a turma toda.

A dificuldade encontrada pelos professores pedagogos que ensinam Matemática para planejar situações pode estar relacionada aos cursos de formação inicial, uma vez que muitos professores concluem cursos de formação sem conhecimentos de conteúdos matemáticos com os quais trabalharão, tanto no que concerne a conceitos quanto aos procedimentos e a própria linguagem Matemática que utilizarão em sua prática docente, conforme afirma Curi (2004).

Fiorentini et al. (2002) corroboram ao afirmar que pesquisas sobre a formação dos professores das séries iniciais do Ensino Fundamental têm mostrado a existência de lacunas em relação à Matemática, principalmente na formação inicial. Por essa razão muitos professores polivalentes encontram dificuldades para ensinar Matemática, sobretudo quando o objetivo é transformas as práticas tradicionais de ensino em um trabalho coerente com a necessidade de desenvolver um trabalho que envolva a todos os estudantes. Esse fato justifica a necessidade de uma formação continuada que se pauta nas necessidades que emergem do cotidiano do grupo, uma formação com formato de organização colaborativo, que favoreça a construção de práticas por meio da reflexão sobre os problemas locais de um contexto específico.

A Matemática deve se tornar acessível para todos os estudantes. Caso apenas um grupo de alunos tenha acesso aos seus conteúdos e os demais sejam considerados incapazes, continuaremos a reforçar os motivos que causam aversão de muitos estudantes em relação a essa disciplina. Os conteúdos devem ser trabalhados de forma contextualizada, 
relacionados às situações cotidianas vivenciadas pelos estudantes, conforme descrevem autores como Pais (2006) e Lorenzato (2006), envolvendo resolução de problemas que tenham sentido para o estudante. É necessário também que os professores entendam que o que faz sentido para um aluno, pode não fazer para outro e que, portanto, não há como estabelecer metas para o outro. Cada um aprenderá algo a partir de uma situação que possibilite a construção do conhecimento de diversos modos e nessas situações não é necessária uma adaptação do ensino para alguns, como afirma Lanuti (2015), mas uma verdadeira reconstrução do ato educativo: do planejamento ao desenvolvimento das atividades, da intencionalidade do professor ao que afeta o aluno, do ensino à aprendizagem: que são processos absolutamente independentes.

\section{Alguns resultados: a transformação da prática docente}

"Ao tentar definir qual a melhor categoria que os meus alunos se encaixavam, eu buscava desenvolver uma análise que, hoje, com esses estudos nos encontros de formação, vejo que é impossível. Não posso considerar apenas a deficiência de uma pessoa e buscar decidir o que é melhor para ela: apontar o que o 'surdo' precisa, como o ‘cego' pode aprender melhor etc. Esses estudos têm me mostrado que a condição de deficiência de uma pessoa é, na verdade, uma deficiência do meio que a gente vive, que precisa se adaptar para que essa pessoa se desenvolva, aprenda as coisas que quiser... Se não existe alguma coisa que define o que é ser normal, como dizer o que é o deficiente? Como posso pensar que meu aluno se resume em uma deficiência?” (Professora A, comunicação verbal, 2016, arquivo do pesquisador) ${ }^{3}$

A fala da professora $\mathrm{A}^{4}$, obtida durante a sua participação em um dos encontros de formação, revela que o estudo realizado sobre a Filosofia da Diferença tem lhe ajudado a perceber que o sujeito não cabe em uma categoria qualquer, que a pessoa se modifica de tal modo que não pode ser reduzida a uma identidade fixada na deficiência e que não é possível indicar o que o outro necessita, o que é melhor para que o outro aprenda. Esse é um dos pontos que aproximam a Filosofia da Diferença à Educação, sobretudo à Educação Inclusiva.

Essa aproximação entre o pensamento deleuzeano e a Educação tem possibilitado aos professores repensarem o modo como ensinam os seus alunos, que como planejam e desenvolvem as suas aulas de Matemática e

3 Depoimento da Professora A, obtido na presença do pesquisador na cidade de Mirante do Paranapanema, SP, Brasil, em maio de 2016.

${ }_{4}$ Foram utilizadas siglas para preservar a identidade das professoras participantes, conforme Termo de Livre Consentimento e Esclarecido (TLCE). 
das demais disciplinas. Entendemos que é necessário desenvolver situações com os estudantes em que eles também possam decidir o que querem fazer, quais são os temas a serem discutidos nas aulas. Temos ressignificado os processos de ensino e de aprendizagem, entendendo que o primeiro se refere à disponibilização de recursos, materiais e informações aos alunos e, o segundo, à criação subjetiva realizada a partir das escolhas que o aprendente faz.

Tendo como base essa perspectiva, o trabalho pedagógico desenvolvido na escola em que a formação ocorre vem sendo planejado, desenvolvido e avaliado sem equivocadas pretensões em relação à aprendizagem dos alunos. O erro deixou de ser visto como um insucesso ou um parâmetro utilizado para punir, nivelar, classificar, distinguir "quem sabe" de quem "não sabe". Ao entenderem essas questões, os professores passaram a questionar, por exemplo, os agrupamentos realizados em sala de aula, em que os alunos são organizados de acordo com supostos "níveis de saberes" - critérios equivocados, fundamentados na busca pela semelhança, na suposta capacidade que o professor tem de mensurar o que os alunos sabem e apontar qual é o saber mais elevado, para nivelá-los

Os professores que participam da formação vêm desenvolvendo situações em que a Matemática faz sentido para toda a turma, que permitem a todos os alunos participarem das atividades sem que haja a necessidade de adaptar o ensino para alguns, pois entendemos essa ação como uma prática perversa, que exclui. Assim, cada um pode participar das atividades da maneira que escolher, sem que o conhecimento construído necessite ser provado, sistematizado como se esperava previamente.

A autoavaliação tem sido desenvolvida para que o aluno possa dizer o que pretende aprender, ao contrário das avaliações somativas que têm como objetivo quantificar o que fora aprendido, desconsiderando o processo de construção do conhecimento. As avaliações tradicionais são formas de monitoramento que nada revelam sobre o que cada um sabe.

Um exemplo dessas situações capazes de envolver a todos os alunos foi uma aula passeio desenvolvida por uma professora participante da formação. De acordo com o currículo utilizado na escola, os alunos deveriam aprender sobre os números, colocando-os em ordem crescente e decrescente. Juntos, professora e alunos, decidiram por fazer uma aula passeio, em que todos pudessem observar os números que faziam parte daquele contexto. A professora sugeriu que os alunos visitassem as outras salas da escola, mas eles insistiram por fazer um passeio na rua, conforme a Imagem 1.5

\footnotetext{
5 Tenho autorização para uso e divulgação de imagens.
} 


\section{Imagem 1 - Alunos realizando um passeio pela cidade}

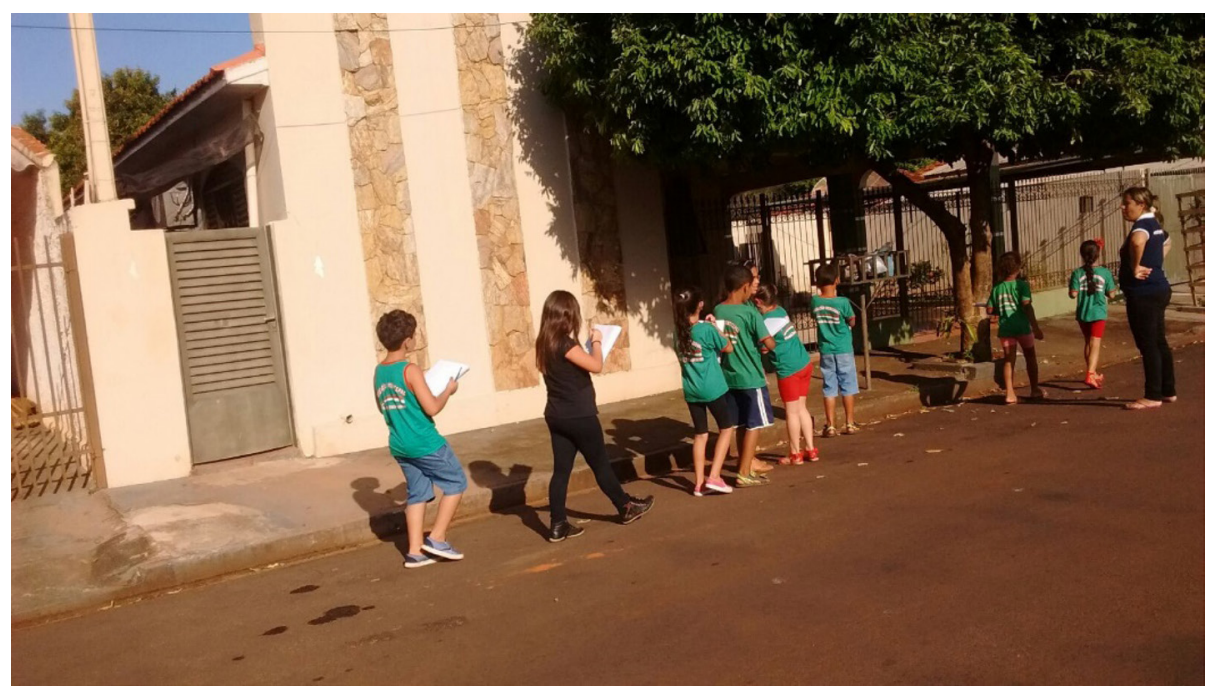

Fonte: Imagem cedida por professora participante da formação ao pesquisador em 2016.

Nessa atividade, a professora deixou os alunos livres para escolherem o que fazer, sem prescrever o que deveriam fazer. Cada um registrou por escrito os números observados em placas, pelas ruas, nos carros etc. e, depois, socializaram com os demais o que haviam visto no passeio.

Alguns alunos disseram que haviam anotado números maiores que mil, o que foi uma surpresa para a professora que afirmou ter ensinado "apenas os números até quinhentos" (Professora E, comunicação verbal) ${ }^{6}$. Outros disseram que perceberam que de um lado da rua os números das casas eram ímpares e outros eram pares e dois alunos contaram aos demais colegas que haviam aprendido que existe números maiores que cem.

Ao filmar essas discussões, tematizando a sua prática, a professora levou para um dos encontros de formação para que todo o grupo pudesse discutir sobre o desenvolvimento da aula passeio. Segundo a própria professora $\mathrm{E}$

6 Depoimento da Professora E, obtido na presença do pesquisador na cidade de Mirante do Paranapanema, São Paulo, Brasil, em junho de 2016. 
(comunicação verbal) ${ }^{7}$, "os alunos foram além dos objetivos que estavam determinados no currículo utilizado e eu pude perceber que eles sabem coisas diferentes e se interessaram por assuntos diferentes também".

Ainda que o currículo ajude no planejamento da aula ao sugerir o tema que pode ser trabalhado, a situação prática e a liberdade dada à turma para discutir sobre o que lhe interessava possibilitou a construção de conhecimentos de um modo autônomo. Essa prática tem a ver com a filosofia da diferença, com a ideia de que cada pessoa aprende de um modo singular e que, portanto, não faz sentido compará-las entre si, dizendo quem é ou são "o(s) diferente(s)". Se não há um padrão de normalidade não há como dizer o que deve ser seguido, copiado.

Considerar a possibilidade de o aluno aprender além do que é ensinado é reconfigurar o papel do ensino, entendido como um processo de acompanhamento do aluno em seu processo de aprendizagem, sem buscar controlálo. Nessa direção, a aprendizagem é entendida como uma criação que advém daquilo que faz sentido para o sujeito e, portanto, não está relacionada a uma reprodução de um saber sistematizado, já existente.

\section{Considerações finais}

A pesquisa de doutorado ainda está em desenvolvimento e as conclusões que tenho são, portanto, parciais. A inclusão escolar é um assunto revolucionário, pois desarranja, enferruja as peças que compõem a máquina-escola binária e ambivalente: é aberta a todos, mas produz os diferentes; busca diferenciar o ensino para determinados alunos com uma suposta preocupação de "ensiná-los melhor", quando na verdade priva - os de fazerem parte do contexto educacional que os demais compõem; busca amenizar o desafio de se trabalhar com a diferença de cada estudante a partir de medidas paliativas que resultam em uma exclusão camuflada.

Nossa luta com a formação proposta é entender os fundamentos de uma escola de todos para estarmos munidos de estratégias para enfrentar esses desafios, sobretudo no que diz respeito ao ensino de Matemática.

A tentativa de aproximar a Filosofia à educação está relacionada à necessidade de compreender as questões de fundo da inclusão. Com isso, esse deixará de ser um tema controverso, pois o mal entendimento do que de fato é incluir, acarreta a perpetuação de um trabalho pedagógico ancorado em preceitos ultrapassados: a classificação, a comparação etc.

Tematizar a prática docente, refletir sobre o trabalho com todos os professores a partir dos problemas locais dessa escola, tem nos possibilitado repensar a ideia de formação docente, que necessita estar direcionada a algumas questões, a saber: a problematização das questões que emergem do cotidiano dos professores, as possibilidades

\footnotetext{
7 Idem.
} 
de se desenvolver um ensino de Matemática para todos os alunos a partir de contexto local, isto é, específico; e a necessidade de trabalhar com a corresponsabilidade, pois todos os professores podem apresentar temas, problemas, ideias e experiências que possibilitam ao outro rever as suas concepções e ações. Precisamos pensar em uma formação que parte das contingências, do que é específico a um determinado espaço, sem buscar generalizar as orientações, como pretendem as macropolíticas.

Estudar a filosofia tem viabilizado a construção de uma prática pedagógica ancorada nos fundamentos de um pensamento pós-crítico, que considera a vida como uma obra de arte, única, imanente, que não tende a uma transcendência. Negar as transcendências tem a ver com a valorização do que real, do momento presente, das condições que se têm para planejar e desenvolver determinadas ações sem esperar o alcance de uma verdade já imposta.

Apesar de certa resistência inicial do professores pedagogos para problematizarem os problemas que emergem do seu cotidiano, temos chegado à conclusão de que é criando saídas contingentes e provisórias para os problemas que encontramos que poderemos transformar a escola e nos transformarmos, como consequência.

Tem sido possível perceber uma mudança de concepção dos professores em relação aos processos de ensino e de aprendizagem, o que tem reconfigurado o real papel da escola, que não é o de regular o que se aprende, mas ensinar considerando a heterogeneidade. Se quisermos uma escola que é de todos os alunos, a diferença deve ser o elemento principal do planejamento pedagógico, da formação docente e das práticas de ensino. Para tal, não podemos continuar apenas a mexer com os personagens e com os seus respectivos papeis dentro de um cenário que está falido. O enredo deve ser outro!

\section{Agradecimentos}

À Fundação de Amparo à Pesquisa do Estado de São Paulo (FAPESP).

\section{Referências}

CURI, E. Formação de professores polivalentes: uma análise do conhecimento para ensinar Matemática e de crenças e atitudes que interferem na constituição desses conhecimentos. 278 f. Tese (Doutorado em Educação Matemática) - Faculdade de Educação Matemática, PUC-SP, São Paulo, 2004. https://doi.org/10.29388/978-85-53111-95-4-0-f.63-68

DELEUZE, G. Bergsonismo. Tradução L. Orlandi. São Paulo: Ed. 34, 1999. 
DELEUZE, G. Conversações. 2. ed. São Paulo: Ed. 34, 2010.

DeleuZE, G. GUATARri, F. Mil Platôs. 2. ed. São Paulo: Ed. 34, 1996. v. 1.

DELEUZE, G. Platão e o Simulacro. In: DELEUZE, G. Lógica do sentido. 4. ed. São Paulo: Perspectiva, 2000, p. $259-271$. (Estudos).

FERREIRA, A. C. O desafio de ensinar - aprender Matemática no noturno: um estudo das crenças de estudantes de uma escola pública de Belo Horizonte. 189 f. Dissertação (Mestrado em Educação) - Universidade Estadual de Campinas, Campinas, 1998. https://doi.org/10.20396/sinteses.v0i7.11567

FIORENTINI, D. et al. Formação de professores que ensinam Matemática: um balanço de 25 anos da pesquisa brasileira. Educação em Revista, Belo Horizonte, n. 36, p.137-160, 2002. https://doi.org/10.1590/0104-4060.68973

GALLO, S. Deleuze \& a Educação. 3. ed. Belo Horizonte: Autêntica Editora, 2016.

GALLO, S. Transversalidade e Educação: Pensando uma Educação Não-disciplinar. In: ALVES, N.; LEITE, R. G. (org.). O Sentido da Escola. Rio de Janeiro: DP\& ${ }^{\mathrm{a}}$, 1999, p. 17-43.

LANUTI, J. E. O. E. Educação Matemática e Inclusão Escolar: a construção de estratégias para uma aprendizagem significativa. 2015. 127 f. Dissertação (Mestrado em Educação) - Universidade Estadual Paulista Júlio de Mesquita Filho, Presidente Prudente, 2015. https://doi.org/10.1590/s2176-6681/278133671

LORENZATO, S. Educação Infantil e percepção matemática. Campinas: Autores Associados, 2006. (Coleção Formação de Professores).

MANTOAN, M. T. E. Ensinando a turma toda - as diferenças na escola. Pátio: revista Pedagógica, [s. l.], ano 5, n. 20, p. 18-23, fev./abr. 2002.

MANTOAN, M. T. E. Inclusão Escolar: O que é? Por quê? Como fazer? São Paulo: Summus, 2014.

MANTOAN, M. T. E. O direito de ser, sendo diferente, na escola. In: RODRIGUES, D. (org.). Inclusão e educação: doze olhares sobre a educação inclusiva. São Paulo: Summus, 2006.

PAIS, L. C. Ensinar e Aprender Matemática. Belo Horizonte: Autêntica, 2006.

SCHÖPKE, R. Por uma filosofia da diferença: Gilles Deleuze, o pensador nômade. Rio de Janeiro: Contraponto, 2012. 
TADEU, T. A arte do encontro e da composição: Spinoza + Currículo + Deleuze. Revista Educação e Realidade, [s. l.], v. 27, n. 2, p. 47-57, jul./dez. 2002.

WEISZ, T; SANCHEZ, A. O diálogo entre o ensino e a aprendizagem. 2. ed. São Paulo: Ática, 2011.

Recebido em: 23/5/2018.

Aprovado em: 20/12/2019

Publicado em: 10/2/2020.

\section{Endereço para correspondência:}

José Eduardo de Oliveira Evangelista Lanuti

Universidade Federal de Mato Grosso do Sul

Av. Capitão Olinto Mancini,1662, sala 14 - Jardim Primaveril

79600-080, Três Lagoas, MS, Brasil

\section{Autor:}

José Eduardo de Oliveira Evangelista Lanuti

Doutor em Educação pela Universidade Estadual de Campinas (UNICAMP, Campinas, SP, Brasil).

Professor da Universidade Federal de Mato Grosso do Sul (UFMS), Três Lagoas, MS, Brasil.

Orcid: http://orcid.org/0000-0001-6055-1494

E-mail: dulanuti@gmail.com 